\title{
Produção de forragem e componentes morfológicos em pastagem de coastcross consorciada com amendoim forrageiro ${ }^{1}$
}

\section{Leandro Martins Barbero ${ }^{2}$, Ulysses Cecato ${ }^{3}$, Simony Marta Bernardo Lugão ${ }^{4}$, José Augusto Nogueira Gomes ${ }^{3}$, Veridiana Aparecida Limão², Kelen Cristina Basso ${ }^{3}$}

\footnotetext{
1 Pesquisa financiada pela Fundação Araucária e Instituto Agronômico do Paraná.

2 Escola Superior de Agricultura "Luiz de Queiroz" - Universidade de São Paulo.

3 Universidade Estadual de Maringá.

4 Instituto Agronômico do Paraná.
}

RESUMO - Objetivou-se avaliar a produção de forragem e a composição morfológica de uma pastagem de coastcross (Cynodon dactylon, cv. Coastcross) consorciada com amendoim forrageiro (Arachis pintoi, cv. Amarillo) com e sem adubação nitrogenada e submetida a pastejo com lotação continua. Utilizou-se um delineamento experimental em blocos ao acaso com parcelas subdivididas no tempo, com duas repetições, para avaliação das seguintes combinações: coastcross + amendoim forrageiro $+200 \mathrm{~kg} / \mathrm{ha}$ de $\mathrm{N}$; coastcross + amendoim forrageiro $+100 \mathrm{~kg} / \mathrm{ha}$ de $\mathrm{N}$; coastcross $+200 \mathrm{~kg} / \mathrm{ha}$ de $\mathrm{N}$ e coastcross + amendoim forrageiro. Para estimar a disponibilidade de massa de forragem e a produção de forragem, foram usadas as técnicas da dupla amostragem e do triplo emparelhamento, respectivamente, a cada 28 dias. Foram avaliadas as proporções de gramínea, leguminosas, invasoras, solo descoberto e liteira. O material da dupla amostragem foi separado em lâmina foliar, bainha+colmo e material morto. A massa de forragem foi menor na pastagem sem adubação com nitrogênio e maior na pastagem adubada com nitrogênio (200 kg/ha) sem amendoim forrageiro. A pastagem sem adubação foi a que apresentou a maior massa de amendoim forrageiro. A produção de forragem foi maior nas pastagens adubadas com nitrogênio na dose de $200 \mathrm{~kg} / \mathrm{ha}$, seguidas da pastagem adubada com $100 \mathrm{~kg}$ de N/ha. A taxa de acúmulo de forragem seguiu a mesma tendência da produção de forragem. Não foram observadas diferenças para solo descoberto, liteira e área descoberta entre as combinações avaliadas, porém na pastagem adubada com nitrogênio na dose de $200 \mathrm{~kg} / \mathrm{ha}$ sem leguminosa, houve menor incidência de plantas invasoras. A razão folha/colmo, massa de folhas e massa de material morto não diferiu entre as pastagens, porém aquela adubada com $200 \mathrm{~kg}$ de N/ha sem leguminosa apresentou maior massa de colmos.

Palavras-chave: forragicultura, gramínea, nitrogênio, produtividade

\section{Forage production and morphological components of coastcross pasture mixed with peanut forage}

ABSTRACT - This experiment was carried out from July 2006 to June 2007. It was used an experimental design of random blocks with split plot in time, with two replications using the following treatments: Coastcross + peanut forage $+200 \mathrm{~kg} / \mathrm{ha}$ of N; Coastcross + Peanut Forage $+100 \mathrm{~kg} / \mathrm{ha}$ of N; Coastcross $+200 \mathrm{~kg} / \mathrm{ha}$ of N and Coastcross + Peanut Forage in the following seasons: winter, spring, summer and autumn. To estimate the forage mass production availability, the double sampling and triple pairing technique, respectively, every 28 days was used. The proportions of grass, legumes, weeds, uncovered soil and litter were evaluated. The material from the double sampling technique was separated into leaf blade, stem + sheath and dead material fractions. Regarding of forage availability, the pasture submitted to treatment without nitrogen had the lower mass, while that submitted to $200 \mathrm{~kg} / \mathrm{ha}$ of nutrient without the presence of legume had the highest forage mass. For the peanut forage mass, the pasture without fertilization presented the best result. The forage production was higher in pastures submitted to treatment with $200 \mathrm{~kg}$ of N/ha followed by that fertilized with $100 \mathrm{~kg}$ of N/ha. The grass accumulation rate followed the same trend of forage production. No difference were observed for uncovered soil, litter and uncovered area between treatments; however, the pasture submitted to the dose of $200 \mathrm{~kg}$ of N/ha without legume presented lower incidence of invasive plants. No differences were observed for the leaf/stem ratio, leaves mass and dead material mass between treatments; however, the grass submitted to $200 \mathrm{~kg}$ of N/ha without legume presented the greatest stems mass.

Key Words: forage crops, grass, nitrogen, productivity 


\section{Introdução}

A produção de forragem depende de fatores inerentes ao ambiente, como temperatura e radiação, e de fatores passíveis de serem alterados pelo homem, como disponibilidade de nutrientes e de água. Além disso, as técnicas de manejo empregadas podem influenciar na dinâmica de produção e uso dessa forragem (Cecato et al., 2006).

O nitrogênio é considerado o mineral de maior importância para as plantas, pois pode proporcionar aumento na disponibilidade de forragem e na quantidade de proteína por hectare. Isso implica dietas mais nutritivas, acréscimo da capacidade de suporte das pastagens e no ganho de peso vivo por hectare (Dias et al., 2000).

A principal forma de fornecer nitrogênio à planta forrageira é pela fertilização química. No entanto a utilização de leguminosas consorciadas com gramíneas pode contribuir com o aporte de nitrogênio para o sistema, via fixação biológica, decorrente da simbiose entre a leguminosa e bactérias do gênero Rhizobium. O nitrogênio fixado é transferido para a leguminosa e disponibilizado ao solo pelo desprendimento dos nódulos e por reciclagem via mineralização da liteira da leguminosa, com possibilidade de ser utilizado pela gramínea, melhorando a produção de forragem. Neste contexto, destaca-se o alto potencial do amendoim forrageiro (Arachis pintoi Krapovickas y Gregori) como estratégia para o suprimento de $\mathrm{N}$ ao ecossistema da pastagem, por reduzir ou dispensar a utilização da adubação nitrogenada com fertilizantes sintéticos ou outras fontes. Resultados quanto a este suprimento foram observados por Miranda (2003), que encontrou valores de 23 a $85 \mathrm{~kg}$ de N/ha/ano, decorrentes da fixação biológica em Arachis pintoi.

O uso da consorciação entre gramíneas e leguminosas pode ser visto como uma opção para o aumento na produtividade de forragem e na rentabilidade e sustentabilidade do sistema de produção de bovinos em regiões de clima tropical (Valentin \& Andrade, 2004). Entretanto, segundo Barcellos et al. (2000), a principal limitação para a introdução de leguminosas em sistemas de produção seria sua baixa persistência na pastagem.

Objetivou-se avaliar a produção de forragem e a composição morfológica de uma pastagem de coastcross (Cynodon dactylon [L] Pers cv. Coastcross) consorciada com amendoim forrageiro (Arachis pintoi Krapovickas y Gregori. cv. Amarillo), com e sem adubação nitrogenada, e submetida a pastejo com lotação contínua.

\section{Material e Métodos}

O experimento foi conduzido na Estação Experimental do IAPAR, em Paranavaí, Paraná, localizada a $23^{\circ} 05^{\prime} \mathrm{S}$ de latitude $52^{\circ} 26^{\prime} \mathrm{W}$ de longitude e uma altitude média de $480 \mathrm{~m}$. O tipo climático predominante na região é o cfa-clima subtropical úmido mesotérmico - pela classificação de Köeppen (IAPAR, 1994), caracterizado pela predominância de verões quentes, baixa freqüência de geadas severas e uma tendência de concentração das chuvas no período da primavera e verão. A temperatura média anual é de $22^{\circ} \mathrm{C}$, a média dos meses mais quentes (janeiro e fevereiro) é de $25^{\circ} \mathrm{C}$ e do mês mais frio (junho) $17,7^{\circ} \mathrm{C}$. A precipitação pluvial anual situa-se em torno de $1.200 \mathrm{~mm}$ (Figura 1).

O solo da área experimental, originado do Arenito Caiuá, é classificado como Latossolo Amarelo distrófico, (Embrapa, 1999), com 88\% de areia, 2\% de silte e 10\% de argila, baixo pH, baixa capacidade de troca catiônica (CTC) e baixo teor de matéria orgânica e de fósforo (Iapar, 1999). No início do período experimental, foram coletadas amostras de solo nas unidades experimentais a uma profundidade de $0-10 \mathrm{~cm}$ (Tabela 1 ).

Este experimento compreendeu o período de 1 de julho de 2006 a 30 de junho de 2007, em uma área já estabelecida com Coastcross consorciada com amendoim forrageiro e que foi utilizada sob pastejo com lotação contínua durante quatro anos e apresentava sinais de degradação, principalmente nos pastos que não recebiam adubação nitrogenada. A área foi de 5,3 ha, subdivididos em oito piquetes com tamanho médio de 0,66 ha.

Foi utilizado um delineamento experimental de blocos ao acaso em parcelas subdivididas, com duas repetições.



Figura 1 - Condições climáticas durante o período experimental (julho de 2006 a junho de 2007). 
Tabela 1 - Resultado da análise de solo da área experimental

\begin{tabular}{lcccccccccrrrr}
\hline Pastagem & $\begin{array}{c}\mathrm{P} \\
\mathrm{mg} / \mathrm{dm}^{3}\end{array}$ & $\begin{array}{c}\mathrm{C} \\
\mathrm{g} / \mathrm{dm}^{3}\end{array}$ & $\mathrm{pH}$ & $\mathrm{Al}$ & $\mathrm{H}+\mathrm{Al}$ & $\mathrm{Ca}$ & $\begin{array}{c}\mathrm{Mg} \\
\mathrm{cmol}_{\mathrm{c}} / \mathrm{dm}^{3} \text { de solo }\end{array}$ & $\mathrm{K}$ & $\mathrm{S}$ & $\begin{array}{c}\mathrm{T} \\
\%\end{array}$ \\
\hline CA200 & 15,5 & 9,2 & 5,0 & 0,3 & 2,9 & 1,4 & 1,1 & 0,2 & 2,4 & 5,6 & 47,6 & 1,0 \\
CA100 & 13,7 & 9,6 & 5,4 & 0,0 & 2,3 & 1,7 & 1,2 & 0,2 & 3,1 & 5,5 & 57,0 & 0,0 \\
C200 & 17,5 & 10,5 & 5,0 & 0,0 & 2,8 & 1,3 & 1,2 & 0,3 & 2,8 & 5,6 & 49,5 & 0,4 \\
CA & 17,6 & 9,9 & 5,6 & 0,0 & 2,2 & 2,0 & 1,3 & 0,3 & 3,6 & 5,9 & 61,1 & 0,0 \\
\hline
\end{tabular}

CA200 $=$ coastcross + amendoim forrageiro $+200 \mathrm{~kg}$ de N/ha/ano; CA100 = coastcross + amendoim forrageiro $+100 \mathrm{~kg}$ de N/ha/ano; C200 = coastcross $+200 \mathrm{~kg}$ de N/ha/ano $\mathrm{CA}=$ coastcross + amendoim forrageiro.

Nas parcelas avaliaram as quatro combinações a seguir: CA200 - coastcross + amendoim forrageiro $+200 \mathrm{~kg}$ de N; CA100 - coastcross + amendoim forrageiro $+100 \mathrm{~kg}$ de N; C200 - coastcross $+200 \mathrm{~kg} / \mathrm{ha}$ de N; CA - coastcross + amendoim forrageiro. Nas subparcelas foram avaliadas as estações do ano: inverno (julho a setembro/2006), primavera (outubro a dezembro/2006), verão (janeiro/2007 a março/ 2007) e outono (abril/2007 a junho/2007).

As aplicações de nitrato de amônio como fonte de nitrogênio foram parceladas em quatro vezes: 8/11/2006, 28/12/2006, 30/1/2007 e 5/3/2007. Juntamente com a primeira adubação nitrogenada, foi realizada a adubação fosfatada, tendo como fonte o superfosfato simples, com intuito de elevar o teor de fósforo a aproximadamente $15 \mathrm{mg} / \mathrm{dm}^{3}$. Também foi realizada a adubação com micronutrientes com o adubo comercial BR 12 na dose de $50 \mathrm{~kg} / \mathrm{ha}$. A adubação potássica foi parcelada junto com a nitrogenada, usando-se o cloreto de potássio como fonte objetivando elevar a saturação de K a 4\% da CTC. Toda a adubação foi realizada a lanço e sempre após precipitação mínima de $30 \mathrm{~mm}$.

A pastagem foi manejada utilizando-se novilhas cruzadas (Red Angus $\times$ Nelore $\times$ Limousin) com peso médio inicial de $170 \mathrm{~kg}$, sob lotação contínua e com carga animal variável, visando manter a pastagem com uma altura média de $17 \mathrm{~cm}$. Para isso, duas vezes por semana tomava-se a altura do pasto em 50 pontos aleatórios em cada unidade experimental e fazia-se o ajuste da lotação de acordo com a técnica do put and take, proposta por Mott \& Lucas (1952).

A taxa de acúmulo de forragem (TAF) e a produção de massa de forragem da pastagem (PMF) foram avaliadas a cada 28 dias, com auxílio de três gaiolas de exclusão de $1 \mathrm{~m}^{2}$ por piquete. A alocação das gaiolas foi feita por meio da técnica do triplo emparelhamento, proposta por Moraes (1991). Para o cálculo da taxa de acúmulo, utilizou-se o método agronômico da diferença, onde é observado o acúmulo de forragem dentro da gaiola de exclusão por um período de 28 dias, conforme equação proposta por Davies et al. (1993).
Para estimar a massa de forragem disponível da pastagem (MF), foi utilizado o método da dupla amostragem descrito por Wilmm (1944) com coletas a cada 28 dias e foram avaliados 20 pontos aleatórios dentro da unidade experimental, dos quais seis pontos foram cortados. O material da dupla amostragem e das gaiolas de exclusão foi cortado rente ao solo, com auxílio de uma seifadora motorizada em uma área de $0,25 \mathrm{~m}^{2}$, e as amostras foram acondicionadas em sacos de papel. Das amostras oriundas da dupla amostragem foram feitas subamostras, destinadas à separação botânica da Coastcross em lâminas foliares (LF), bainha + colmo (BC) e material morto (MM) e planta inteira do amendoim forrageiro (AF), as quais foram utilizadas para estimar a matéria seca da pastagem pela secagem do material em estufa de circulação de ar a $65^{\circ} \mathrm{C}$ por 72 horas, até peso constante.

Após a determinação, em matéria seca, de cada constituinte da forragem coletada, pôde-se estimar a massa de forragem disponível da pastagem (MF), a massa de amendoim forrageiro (MAF), a razão folha/colmo (RF/C), a massa de lâminas foliares (MLF), a massa de colmos (MC), a massa de material morto (MM), a taxa de acúmulo de forragem (TAF), a produção de massa de forragem da pastagem (PMF).

Com a dupla amostragem, foi feita uma avaliação visual nos 20 pontos escolhidos para estimação da presença de invasoras (INV), solo descoberto (SD), liteira (LIT) e área descoberta (AD), que é o somatório de SD e LIT.

As variáveis avaliadas foram analisadas estatisticamente por meio do programa estatístico SAS (1999), obedecendo ao modelo estatístico: $\mathrm{Y}_{\mathrm{ijk}}=\mu+\mathrm{T}_{\mathrm{i}}+\mathrm{P}_{\mathrm{j}}+\mathrm{B}_{\mathrm{k}}+\mathrm{TP}_{\mathrm{ij}}+$ $e_{i j k}$, em que $Y_{i j k}=$ valor observado no piquete que recebeu o tratamento i, recebendo o efeito do período j e encontra-se no bloco $\mathrm{k} ; \mu$ = média geral; $\mathrm{T}_{\mathrm{i}}=$ efeito do tratamento com i variando de 1 a $4 ; \mathrm{P}_{\mathrm{j}}=$ efeito do período, com $\mathrm{j}$ variando de 1 a $4 ; B_{k}=$ efeito do bloco, com $\mathrm{k}$ variando de 1 a 2 ; $\mathrm{TP}_{\mathrm{ij}}=$ efeito da interação tratamento $\times$ período; $\mathrm{e}_{\mathrm{ijk}}=$ erro aleatório associado a cada observação. As médias foram submetidas ao teste Tukey a 5\% de probabilidade. 


\section{Resultados e Discussão}

Para a produção de massa de forragem (PMF) houve interação tratamento $\times$ estações (Tabela 2), evidenciando que os pastos com a maior dose de adubação nitrogenada, consorciados ou não, tiveram resultados superiores, principalmente em comparação à pastagem consorciada que não recebia adubação, a qual teve resposta semelhante à de todos os pastos, somente no outono. Isto evidencia a importância do adequado aporte de nitrogênio vindo da adubação química sobre a produção de massa de forragem.

Em contrapartida, os dados sugerem que, com o consórcio, pode-se alcançar boas produções, entretanto somente a leguminosa não supre um aporte de nitrogênio suficiente para se produzir forragem como nos pastos bem adubados.

Na primavera e no verão, tanto para os capins adubados quanto para o não adubado, ocorreram produções de massa de forragem semelhantes, porém, superiores às outras estações, como esperado para gramínea e leguminosa de clima tropical. As menores PMF ocorreram no outono, seguido do inverno, em razão da baixa precipitação pluvial nestas épocas (Figura 1). Os melhores resultados nas estações de crescimento ocorrem porque na primavera o perfilhamento é acelerado pelas condições favoráveis de temperatura, precipitação pluvial e fotoperíodo crescente e pelo início da fertilização química, o que proporciona ao pasto condições favoráveis ao rápido desenvolvimento de novos tecidos e órgãos na planta, que, somados, resultam em uma produção de forragem elevada se comparada ao outono e inverno.

Nas estações do inverno e outono, mesmo com a produção menor, esta produção corespondeu a 30\% da PMF anual, comprovando que a correta aplicação do nitrogênio, parcelando-o estrategicamente durante as estações de primavera e verão e aplicando-o no final do verão proporciona à planta condições para produções razoáveis em regiões de condições climáticas favoráveis. Esses resultados confirmam os obtidos por Lenzi (2007) e Paris (2006) trabalhando com coastcross consorciada com amendoim forrageiro.

Ribeiro (2007), avaliando a consorciação entre coastcross e amendoim forrageiro, observou que as pastagens com menores doses de adubação ou só consorciadas foram produtivas, mas apresentaram sempre menor produção de forragem, em virtude da lenta recuperação após o inverno, todavia, demonstrando que a associação entre leguminosa e adubação nitrogenada pode ser benéfica ao sistema, pois proporciona condições para boa produção de

Tabela 2 - Produção, taxa de acúmulo e massa de forragem em pastagem de coastcross consorciada com amendoim forrageiro, adubada ou não com nitrogênio

\begin{tabular}{|c|c|c|c|c|c|c|}
\hline Estação do ano & CA200 & CA100 & $\mathrm{C} 200$ & CA & Média & CV (\%) \\
\hline \multicolumn{7}{|c|}{ Produção de massa de forragem (kg de MS/ha/ano) } \\
\hline Inverno & 3.709ABb & $3.205 \mathrm{ABb}$ & $4.222 \mathrm{Ab}$ & $2.620 \mathrm{Bb}$ & 3.439 & 9,65 \\
\hline Primavera & $6.060 \mathrm{Aa}$ & $5.034 \mathrm{Ba}$ & 5.779Aab & $4.413 \mathrm{Ca}$ & 5.321 & 2,78 \\
\hline Verão & $6.361 \mathrm{Aa}$ & $5.496 \mathrm{ABa}$ & $6.488 \mathrm{Aa}$ & $4.483 \mathrm{Ba}$ & 5.707 & 7,52 \\
\hline Outono & $1.949 \mathrm{Ac}$ & $1.822 \mathrm{Ac}$ & $1.946 \mathrm{Ac}$ & $1.640 \mathrm{Ab}$ & 1.839 & 8,56 \\
\hline Total & 18.079 & 15.557 & 18.434 & 13.156 & & \\
\hline CV (\%) & 3,9 & 5,54 & 8,54 & 10,04 & & 9,64 \\
\hline \multicolumn{7}{|c|}{ Taxa de acúmulo (kg de MS/ha/dia) } \\
\hline Inverno & $41 \mathrm{ABb}$ & $35 \mathrm{ABb}$ & $46 \mathrm{Ab}$ & $29 B b$ & 37 & 24,89 \\
\hline Primavera & $66 \mathrm{Aa}$ & $55 \mathrm{Aa}$ & $63 \mathrm{Aba}$ & $48 \mathrm{Aa}$ & 58 & 30,13 \\
\hline Verão & $71 \mathrm{Aa}$ & $61 \mathrm{ABa}$ & $72 \mathrm{Aa}$ & $50 \mathrm{Ba}$ & 64 & 20,12 \\
\hline Outono & $21 \mathrm{Ab}$ & $20 \mathrm{Ab}$ & $21 \mathrm{Ac}$ & $18 \mathrm{Ab}$ & 20 & 25,17 \\
\hline Média & 50 & 43 & 51 & 36 & & \\
\hline CV (\%) & 25,32 & 26,28 & 26,32 & 30,15 & & 26,8 \\
\hline \multicolumn{7}{|c|}{ Massa de forragem (kg de MS/ha) } \\
\hline Inverno & 2.829 & 2.180 & 3.436 & 2.734 & 2.795 & 36,6 \\
\hline Primavera & 2.654 & 2.933 & 3.172 & 2.416 & 2.794 & 30,62 \\
\hline Verão & 3.167 & 3.190 & 3.771 & 3.503 & 3.408 & 25,4 \\
\hline Outono & 2.689 & 3.484 & 3.540 & 2.186 & 2.975 & 42,01 \\
\hline Média & $2.835 \mathrm{AB}$ & $2.947 \mathrm{AB}$ & $3.480 \mathrm{~A}$ & $2.709 \mathrm{~B}$ & & \\
\hline CV (\%) & 34,9 & 34,66 & 29,32 & 34,63 & & 31,13 \\
\hline
\end{tabular}

Médias seguidas de letras diferentes, maiúsculas nas linhas e minúsculas nas colunas, diferem estatisticamente, entre si, a 5\% de probabilidade pelo teste de Tukey. CA200 $=$ coastcross + amendoim forrageiro $+200 \mathrm{~kg}$ de N/ha/ano; CA100 = coastcross +amendoim forrageiro $+100 \mathrm{~kg}$ de N/ha/ano; C200 = coastcross $+200 \mathrm{~kg}$ de N/ha/ano; $\mathrm{CA}=$ coastcross + amendoim forrageiro. $\mathrm{CV}=$ coeficiente de variação. 
forragem e massa de forragem disponível aos animais suficiente para se manter alta lotação animal em comparação a pastagens que não recebem adubação e não são consorciadas com leguminosas.

A taxa de acúmulo de forragem (TAF) teve comportamento semelhante ao da PMF (Tabela 3) e foi mais elevada nos pastos que receberam adubo nitrogenado, especialmente na época de primavera e verão, pois o efeito do nitrogênio em proporcionar à gramínea a característica de perfilhamento acelerado, especialmente na primavera, associado à luminosidade que atinge as gemas basilares, faz com que nestas épocas a quantidade de perfilhos seja elevada e com alta quantidade de folhas por unidade de área. Assim, espera-se que em pastos recebendo adubação haja elevada interceptação de radiação solar incidente pelas folhas, o que reflete elevada PMF e partição de fotoassimilados dentro da planta, resultando no produto final, que é a elevada TAF e PMF total (Tabela 2).

O outono proporcionou condições desfavoráveis à TAF e foi seguido do inverno, que está relacionado à baixa pluviosidade, luminosidade e temperatura. Tanto para a PMF quanto para a TAF no outono, não foi observada diferença significativa entre os tratamentos, pois nessa época o potencial de resposta à adubação nitrogenada diminuí, pois as condições climáticas são desfavoráveis.

Carnevalli et al. (2001), trabalhando com coastcross em pastejo com lotação contínua, obtiveram TAF de 60,4 a $71,9 \mathrm{~kg}$ de MS/ha/dia em avaliações realizadas nas estações da primavera e verão. Realizando avaliações nestas mesmas estações, Scaravelli et al. (2007) encontraram para o coastcross TAF de 33,05 a 176,20 kg de MS/ha/dia, utilizando $80 \mathrm{~kg}$ de N/ha/ano. Esses dados comprovam que a TAF pode variar de acordo com a adubação utilizada, a época do ano ou a localização geográfica.

Tabela 3 - Massa de forragem de amendoim forrageiro (kg de MS/ha) em pastagem consorciada com coastcross, adubada ou não com nitrogênio

\begin{tabular}{lccccc}
\hline \multirow{2}{*}{ Estação do ano } & \multicolumn{3}{c}{ Tratamento } & Média & CV (\%) \\
\cline { 2 - 4 } & CA200 & CA100 & CA & & \\
\hline Inverno & $59 \mathrm{Ac}$ & $48 \mathrm{Aa}$ & $69 \mathrm{Ab}$ & 59 & 31,91 \\
Primavera & $173 \mathrm{Ba}$ & $167 \mathrm{Ba}$ & $251 \mathrm{Aab}$ & 197 & 22,44 \\
Verão & $135 \mathrm{Bab}$ & $179 \mathrm{Ba}$ & $580 \mathrm{Aa}$ & 298 & 26,75 \\
Outono & $105 \mathrm{Bbc}$ & $87 \mathrm{Ba}$ & $403 \mathrm{Aab}$ & 198 & 20,75 \\
Média & 118 & 120 & 326 & & \\
CV (\%) & 11,81 & 29,99 & 38,65 & & 21,78
\end{tabular}

Médias seguidas de letras diferentes, maiúsculas nas linhas e minúsculas nas colunas, diferem estatisticamente, entre si, a $5 \%$ de probabilidade pelo teste de Tukey. CA200 = coastcross + amendoim forrageiro $+200 \mathrm{~kg}$ de N/ha/ano; CA100 $=$ coastcross + amendoim forrageiro $+100 \mathrm{~kg}$ de N/ha/ano; CA = coastcross + amendoim forrageiro. CV = coeficiente de variação.
A massa de forragem disponível (MF) (Tabela 2) foi mais elevada nas pastagens de coastcross adubadas com maior quantidade de nitrogênio, porém naquelas em consórcio com e sem adubação, a massa de forragem foi semelhante, o que indica que as pastagens submetidas a déficit de $\mathrm{N}$, quando manejadas a alturas semelhantes a pastagens adubadas, proporcionam quantidade inferior de forragem, conseqüentemente com quantidade inferior de nutrientes, acarretando menor desempenho animal. Essa massa de forragem inferior decorre da menor emissão de perfilhos e acarreta menor densidade dentro do pasto.

Outro fator que deve ser considerado é que pode ocorrer competição por área entre a leguminosa e a gramínea. Nos locais em que existe a leguminosa, a densidade da forragem pode ser menor, pois a estrutura morfológica da leguminosa, que possui crescimento prostrado, faz com que, no plano vertical do dossel forrageiro o volume de espaço não ocupado por estruturas de plantas, principalmente a gramínea, seja maior que na gramínea exclusiva, diminuindo a densidade de forragem. Embora a coastcross tenha crescimento estolonífero/rizomatoso, seus perfilhos são emitidos verticalmente, fazendo com que a ocupação do espaço vertical por estes perfilhos seja maior quando não estão em consorciação e impedindo a competição com outra espécie. Não se observou diferenças na massa de forragem entre as épocas do ano, as quais não influenciaram a quantidade de massa disponível aos animais.

A massa de forragem de amendoim forrageiro obtida (Tabela 3) foi mais elevada na pastagem que não recebeu adubação nitrogenada. Este comportamento ocorre pelo fato de gramínea e a leguminosa serem plantas de metabolismo $\mathrm{C}_{4}$ e $_{3}$, respectivamente, que, quando submetidas a adubações com nitrogênio, têm resposta diferente a este nutriente. A gramínea é mais responsiva e faz com que o processo de competição que vai gerar a persistência da planta forrageira possibilite a gramínea superioridade em relação à leguminosa. A característica de maior participação da leguminosa em pastos não adubados com nitrogênio é um dos fatores que permitem a persistência desta espécie no consórcio e, segundo Perez (2003), embora a seletividade dos animais seja um fator-chave no consórcio, outros fatores devem ser considerados, por exemplo, a capacidade de acumulação de forragem entre as espécies, que deve ser entendida de modo que permita à leguminosa exercer competição com a gramínea, tornando-se estável no consórcio.

Na primavera e no verão, a MAF foi mais elevada que nas outras épocas para os pastos sem adubação em relação aos adubados com nitrogênio, sendo que o outono houve produção de MAF intermediárias a estas épocas. Por ser 
o amendoim forrageiro uma leguminosa tropical fica nítido o efeito da temperatura, luminosidade e pluviosidade observados nas estações da primavera e verão nos resultados de disponibilidade de massa de forragem, fazendo com que nestas épocas a leguminosa mostre seu potencial no consórcio, fixando maior quantidade de $\mathrm{N}$ e contribuindo mais na dieta animal, por estar mais presente na pastagem que as outras épocas do ano. Em trabalho realizado por Andrade et al. (2006) em consórcio de amendoim forrageiro com capim-massai, a porcentagem da leguminosa aumentou progressivamente ao longo do período experimental, sobretudo nas pastagens mantidas com dossel mais baixo e mais aberto.

Na composição morfológica da pastagem, a razão folha/colmo (RF/C) (Tabela 4) foi semelhante entre os pastos adubados e não adubados, comprovando que o manejo adequado da pastagem contribuiu para a constante emissão de folhas em todos os pastos à medida que estes são pastejados. Embora o nitrogênio possa proporcionar condições para maior produção de massa de forragem pela maior produção de lâminas foliares, também proporciona produção de colmos, que, como as lâminas foliares, são constituintes dos perfilhos, e fazem com que no final uma alta produção de massa de forragem tenha a mesma quantidade relativa de folhas em relação a baixa produção de massa de forragem.

Na primavera a relação folha/colmo foi maior que nas outras estações, e nestas foram semelhantes entre elas. Isto ocorreu porque na primavera se inicia o rebrote das plantas forrageiras tropicais, que passaram por um período de escassez de água, luz e temperatura, acelerando-se o processo de formação de lâminas foliares e perfilhamento com o intuito de aumentar rapidamente a área foliar (IAF), fazendo com que este comportamento proporcione à pastagem elevada participação de folhas em sua composição.

Tabela 4 - Razão folha/colmo em pastagem de coastcross consorciada com amendoim forrageiro, adubada ou não com nitrogênio

\begin{tabular}{|c|c|c|c|c|c|c|}
\hline \multirow[t]{2}{*}{ Estação do ano } & \multicolumn{4}{|c|}{ Tratamento } & \multirow[t]{2}{*}{ Média } & \multirow[t]{2}{*}{ CV (\%) } \\
\hline & CA200 & CA100 & C200 & CA & & \\
\hline Inverno & 0,51 & 0,51 & 0,47 & 0,44 & $0,48 b$ & 51,35 \\
\hline Primavera & 0,83 & 0,81 & 0,73 & 0,64 & $0,75 a$ & 36,26 \\
\hline Verão & 0,44 & 0,53 & 0,43 & 0,57 & $0,49 b$ & 40,35 \\
\hline Outono & 0,40 & 0,45 & 0,46 & 0,42 & $0,43 b$ & 32,05 \\
\hline Média & 0,55 & 0,57 & 0,52 & 0,52 & & \\
\hline CV (\%) & 39 & 33,58 & 43,6 & 39,76 & & 38,98 \\
\hline
\end{tabular}

Médias seguidas de letras diferentes, minúsculas nas colunas, diferem estatisticamente, entre si, a 5\% de probabilidade pelo teste de Tukey. CA200 $=$ coastcross + amendoim forrageiro $+200 \mathrm{~kg}$ de N/ha/ano; CA100 $=$ coastcross + amendoim forrageiro $+100 \mathrm{~kg}$ de N/ha/ano; $\mathrm{CA}=$ coastcross + amendoim forrageiro. $\mathrm{CV}=$ coeficiente de variação.
Cecato et al. (2001) avaliaram a RF/C do Coastcross sem nitrogênio e submetido à dose de $400 \mathrm{~kg}$ de N/ha/ano e encontraram valores na ordem de 0,60. Alvim \& Botrel (2001), avaliando a RF/C do coastcross sob pastejo em lotação intermitente, encontraram valores de 1,43 e 0,73 para a época das águas e secas, respectivamente.

A massa de lâminas foliares (MLF) foi semelhante entre os tratamentos que receberam ou não adubação, entretanto, para as estações do ano, o maior acúmulo de MLF ocorreu na primavera, maior que no verão, seguido do outono e inverno (Tabela 5). Este fato justifica-se pelas mesmas razões discutidas anteriormente, para PMF, $\mathrm{MF}$ e RF/C.

Para massa de colmos (MC) do pasto adubado com 200 kg de nitrogênio sem a leguminosa, obteve-se o maior valor médio durante o ano (Tabela 5). Este fato não determina a característica desta forragem ser de menor qualidade por ter grande quantidade de colmos, visto que a RF/C foi semelhante à dos pastos submetidos aos outros tratamentos. Neste caso, a disponibilidade total de massa provavelmente foi maior, em virtude da adubação nitrogenada, que proporcionou maior disponibilidade de massa de forragem e maior massa de colmos.

A massa de material morto (MM) disponível na pastagem foi semelhante nos pastos adubados e não adubados (Tabela 5). Todavia nas estações, a primavera foi a que

Tabela 5 - Massa de lâmina foliar, colmo e material morto (kg de $\mathrm{MS} / \mathrm{ha}$ ) em pastagem de coastcross consorciada com amendoim forrageiro, adubada ou não com nitrogênio

\begin{tabular}{|c|c|c|c|c|c|c|}
\hline \multirow[t]{2}{*}{ Estação do } & no & \multicolumn{3}{|c|}{ Tratamento } & \multirow[t]{2}{*}{ Média } & \multirow[t]{2}{*}{ CV (\%) } \\
\hline & CA200 & CA100 & C200 & CA & & \\
\hline Inverno & 534 & 454 & 677 & 482 & $545 c$ & 52,82 \\
\hline Primavera & 939 & 926 & 1029 & 836 & $929 a$ & 39,15 \\
\hline Verão & 664 & 813 & 789 & 700 & $739 b$ & 57,52 \\
\hline Outono & 355 & 482 & 789 & 576 & $558 \mathrm{bc}$ & 47,83 \\
\hline Média & 639 & 665 & 821 & 645 & & \\
\hline CV (\%) & 42,8 & 47,81 & 51,88 & 42,43 & & 44,87 \\
\hline Inverno & 940 & 956 & 1.613 & 1.253 & 1.196 & 60,41 \\
\hline Primavera & 1.181 & 1.124 & 1.413 & 1.361 & 1.262 & 29,72 \\
\hline Verão & 1.523 & 1.533 & 1.720 & 1.249 & 1.500 & 31,49 \\
\hline Outono & 893 & 1.225 & 1.746 & 1.429 & 1.338 & 48,94 \\
\hline Média & $1.161 \mathrm{~B}$ & $1.201 \mathrm{~B}$ & $1.619 \mathrm{~A}$ & $1.316 \mathrm{~B}$ & & 36,27 \\
\hline CV (\%) & 36,72 & 42,3 & 42,45 & 38,42 & & 36,28 \\
\hline Inverno & 1.263 & 959 & 958 & 1.027 & $1.062 \mathrm{ab}$ & 69 \\
\hline Primavera & 860 & 866 & 1.168 & 1.007 & $973 b$ & 39,96 \\
\hline Verão & 1.170 & 1.110 & 1.257 & 1.417 & $1.236 \mathrm{a}$ & 31,63 \\
\hline Outono & 844 & 960 & 1.143 & 1.419 & $1.096 \mathrm{ab}$ & 43,37 \\
\hline Média & 1.043 & 971 & 1.136 & 1.218 & & \\
\hline CV (\%) & 52,58 & 42,89 & 38,74 & 38,55 & & 42,62 \\
\hline
\end{tabular}

Médias seguidas de letras diferentes, maiúsculas nas linhas e minúsculas nas colunas, diferem estatisticamente entre si a 5\% de probabilidade pelo teste de Tukey. CA200 $=$ coastcross + amendoim forrageiro $+200 \mathrm{~kg}$ de N/ha/ano; CA100 $=$ coastcross + amendoim forrageiro $+100 \mathrm{~kg}$ de $\mathrm{N} / \mathrm{ha} / \mathrm{ano} ; \mathrm{CA}=$ coastcross + amendoim forrageiro. $\mathrm{CV}$ = coeficiente de variação. 
menos proporcionou à pastagem condições para que se acumulasse este componente. No entanto, a disponibilidade média de MM em relação a MF foi de 37, 32, 32 e 45\% de MM nas pastagens submetidas ao CA200, CA100, C200 e CA, respectivamente, demonstrando que a oferta de material de boa qualidade aos animais é possível em pastagens com bom aporte de nutrientes. Carnevalli et al. (2001), trabalhando com coastcross exclusivo, obtiveram valores semelhantes, de 36,2; 35,7; 40,0 e 43,4\% para pastagens manejadas a 5, 10, 15 e $20 \mathrm{~cm}$, respectivamente. Todavia, tanto no estudo de Carnevalli et al (2001) quanto neste trabalho, a dieta dos animais provavelmente continha quantidade inferior a este percentual de MM, em razão do caráter seletivo dos ruminantes em pastejo (Lemaire, 2001).

A porcentagem de solo descoberto e solo coberto com liteira e área descoberta não foi influenciada pelo uso ou não da adubação nitrogenada nos pastos (Tabela 6). Entretanto, o pasto sem leguminosa adubado com $200 \mathrm{~kg}$ de N/ha/ano apresentou a menor quantidade de plantas invasoras.

O outono foi a estação do ano que proporcionou condições ideais para o desenvolvimento e caracterização destes parâmetros de degradação da pastagem. A presença de plantas invasoras na pastagem foi inferior a 10\% entre os tratamentos e épocas do ano, o que confirma os dados obtidos por Scaravelli et al. (2007), que afirmaram que a vantagem da coastcross na competição com outras espécies está ligada à perenidade da espécie e, principalmente, ao seu hábito de crescimento estolonífero.

Tabela 6 - Porcentagem de plantas invasoras, solo descoberto, liteira e área descoberta em pastagem de coastcross consorciada com amendoim forrageiro e adubada ou não com nitrogênio

\begin{tabular}{lccccc}
\hline & \multicolumn{4}{c}{ Tratamento } & \multirow{2}{*}{ CV (\%) } \\
\cline { 2 - 5 } & CA200 & CA100 & C200 & CA \\
\hline Plantas invasoras & 5,82A & 4,75A & 2,09B & 5,00A & 58,42 \\
Solo descoberto & 1,71A & 1,53A & 1,12A & 1,52A & 67,58 \\
Liteira & 5,13A & 4,3A & 4,76A & $5,53 \mathrm{~A}$ & 30,77 \\
Área descoberta & 6,84A & 5,84A & 5,89A & 7,06A & 36,1 \\
\hline \multicolumn{5}{c}{ Estação } & \multicolumn{3}{c}{ CV (\%) } \\
\cline { 2 - 5 } & Inverno & Primavera & Verão & Outono \\
\hline Plantas invasoras & 2,43B & 4,37B & 3,35B & 7,51A & 58,42 \\
Solo descoberto & 1,06B & 0,53B & 1,24B & 3,06A & 67,58 \\
Liteira & 4,71B & 4,91AB & 3,22B & 6,89A & 30,77 \\
Área descoberta & 5,76B & 5,44B & 4,47B & 9,95A & 36,10 \\
\hline
\end{tabular}

Médias seguidas de letras diferentes, maiúsculas nas linhas, diferem estatisticamente, entre si, a 5\% de probabilidade pelo teste de Tukey. CA200 $=$ coastcross + amendoim forrageiro $+200 \mathrm{~kg}$ de N/ha/ano; CA100 = coastcross + amendoim forrageiro $+100 \mathrm{~kg}$ de $\mathrm{N} / \mathrm{ha} / \mathrm{ano} ; \mathrm{CA}=$ coastcross + amendoim forrageiro. $\mathrm{CV}=$ coeficiente de variação.

\section{Conclusões}

O uso de adubação nitrogenada em plantas em consórcio associadas a condições climáticas adequadas propicia elevadas produções de massa de forragem, entretanto a disponibilidade de massa da leguminosa é mais elevada sem a presença do nitrogênio. A estação da primavera promove condições favoráveis para maior disponibilidade de massa de folhas e aumenta a quantidade desse componente em relação aos colmos. No entanto, o consórcio dessa gramínea e adubação não promovem diferença nesses componentes. O uso de consorciações possibilita aumento na produtividade de forragem, mas não permite altos índices de produção comparados aos de pastagens bem adubadas.

\section{Literatura Citada}

ALVIM, M.J.; BOTREL, M.A. Efeitos de doses de nitrogênio na produção de leite de vacas em pastagem de coastcross. Pesquisa Agropecuária Brasileira, v.36, n.3, p.577-583, 2001.

ANDRADE, C.M.S.; GARCIA, R.; VALENTIM, J.F. et al. Grazing management strategies for massaigrass-forage peanut pastures: 1. Dynamics of sward condition and botanical composition. Revista Brasileira de Zootecnia, v.35, n.2, p.334-342, 2006. BARCELLOS, A.O.; ANDRADE, R.P.; KARIA, C.T. et al. Potencial e uso de leguminosas forrageiras dos gêneros Stylosanthes, Arachis e Leucaena. In: SIMPÓSIO SOBRE MANEJO DA PASTAGEM, 17., 2000, Piracicaba. Anais... Piracicaba: Fundação de Estudos Agrários Luiz de Queiroz, 2000, p.297357.

CARNEVALLI, R.S.; Da SILVA, S.C.; FAGUNDES, J.L. et al. Desempenho de ovinos e respostas de pastagens de tifton 85 (Cynodon spp.) sob lotação contínua. Scientia Agrícola, v.58, n.1, p.7-15, 2001.

CECATO, U.; SANTOS, G.T.; MACHADO, F.A. et al. Avaliação de cultivares do gênero Cynodon com e sem nitrogênio. Acta Scientiarum, v.23, n.4, p.781-788, 2001.

CECATO, U.; GALBEIRO, S.; GOMES, J.A.N. et al. Utilização e manejo de pastos de Panicum e Brachiaria em sistemas pecuários. In: BRANCO, A.F; SANTOS, G.T.; JOBIM, C.C. et al. (Eds.). Sustentabilidade em sistemas pecuários. Maringá: Universidade Estadual de Maringá, 2006. p.147-178.

DAVIES, D.A.; FORTHERGILL, M.; MORGAN, C.T. Assessment of contrasting perennial ryegrass, with and without white clover, under continuous sheep stocking in the uplands. 5. Herbage production, quality and intake in years 46. Grass and Forage Science, v.48, p.213-222, 1993.

DIAS, P.F.; ROCHA, G.P.; ROCHA FILHO, R.R.; et al. Produção e valor nutritivo de gramíneas forrageiras tropicais avaliadas no período das águas, sob diferentes doses de nitrogênio. Ciência Agrotecnológica, v.24, n.1, p.260-271, 2000.

EMPRESA BRASILEIRA DE PESQUISA E AGROPECUÁRIA EMBRAPA. Centro Nacional de Pesquisa de Solos. Sistema brasileiro de classificação de solos. Brasília, 1999. 412p.

FAGUNDES, J.L.; DA SILVA, S.C.; PEDREIRA, C.G.S. et al. Índice de área foliar, coeficiente de extinção luminosa e acumulo de forragem em pastagem de Cynodon spp. Sob lotação continua. Pesquisa Agropecuária Brasileira, v.36, n.1, p.187-195. 2001. INSTITUTO AGRONÔMICO DO PARANÁ - IAPAR. Cartas climáticas do Estado do Paraná 1994. Londrina: IAPAR, 1994. 49p. 
INSTITUTO AGRONÔMICO DO PARANÁ - IAPAR. Boletim Técnico 33. Londrina: 1999. p.29.

LEMAIRE, G. Ecophysiology of grasslands: Dynamic aspects of forage plant populations in grazed swards. In: INTERNATIONAL GRASSLAND CONGRESS, 19., 2001, São Pedro. Proceedings... São Pedro: Fundação de Estudos Agrários Luiz de Queiroz, 2001. p.29-37.

LENZI, A. Caracterização da pastagem, desempenho animal e viabilidade econômica em coastcross consorciado ou não com Arachis pintoi. 2007. 119f. Tese (Doutorado em Zootecnia) - Universidade Estadual de Maringá, Maringá, 2007.

MIRANDA, C.H.; VIEIRA, A.; CADISCH, G. Determinação da fixação biológica de nitrogênio no amendoim forrageiro (Arachis spp.) por intermédio da abundância natural de ${ }^{15} \mathrm{~N}$. Revista Brasileira de Zootecnia, v.32, n.6, p.1859-1865, 2003 (supl. 2)

MORAES, A. Produtividade animal e dinâmica de uma pastagem de pangola (Digitaria decumbens Stent), azevém (Lolium multiflorum Lam.) e trevo branco (Trifolium repens L.), submetida a diferentes pressões de pastejo. 1991. 200f. Tese (Doutorado em Zootecnia) - Universidade Federal do Rio Grande do Sul, Porto Alegre, 1991.

MOTT, G.O.; LUCAS, H.L. The design, conduct and interpretation of grazing trials on cultivated and improved pastures. In: INTERNATIONAL GRASSLAND CONGRESS, 6., Pasadena, 1952. Proceedings... Pasadena: 1952. p.1380-1385.

PARIS, W. Produção animal em pastagens de Coastcross-1 consorciada com Arachis pintoi com e sem adubação nitrogenada. 2006. 109f. Tese (Doutorado em Zootecnia) Universidade Estadual de Maringá, Maringá, 2006.
PEREZ, N.B. Melhoramento genético de leguminosas de clima temperado - alfafa (Medicavo sativa L.) e cornichão (Lotus corniculatus L.) - para aptidão ao pastejo. 2003. 175f. Tese (Doutorado em Zootecnia) - Universidade Federal do Rio Grande do Sul, Porto Alegre, 2003.

PROHMAN, P.E.F.; BRANCO, A.F.; JOBIM, C.C. et al. Suplementação de bovinos em pastagem de coastcross (Cynodon dactylon (L.) Pers) no verão. Revista Brasileira de Zootecnia, v.33, n.3, p.792-800, 2004.

RIBEIRO, O.L. Produção animal e características da pastagem de coastcross consorciada com Arachis pintoi, com e sem nitrogênio. 2007. 72f. Dissertação (Mestrado em Zootecnia) Universidade Estadual de Maringá, Maringá, 2007.

ROCHA, G.P.; EVANGELISTA, A.R.; LIMA, J.A. et al. Adubação nitrogenada em gramíneas do gênero Cynodon. Revista Brasileira de Ciência Animal, v.3, n.1, p.1-9, 2002.

STATISTICAL ANALYSIS SYSTEM -SAS. SAS/STAT Procedure guide for personal computers. Version 5. Cary: SAS Institute, 1999. (CD-ROM).

SCARAVELLI, L.F.B.; PEREIRA, L.E.T.; OLIVO, C.J. et al. Produção e qualidade de pastagens de Coastcross- 1 e milheto utilizadas com vacas leiteiras. Ciência Rural, v.37, n.3, p.841-846, 2007.

VALENTIM, J.F.; ANDRADE, C.M.S. Perspectives of grass-legume pastures for sustainable animal production in the tropics. In: REUNIÃO ANNUAL DA SOCIEDADE BRASILEIRA DE ZOOTECNIA, 40., 2004, Campo Grande. Anais... Campo Grande: Sociedade Brasileira de Zootecnia, 2004. p.142-154.

WILM, H.G.; COSTELLO, D.F.; KLIPPLE, G.E. Estimating forage yield by the double-sampling methods. Journal of American Society of Agronomy, v.36, p.194-203, 1944. 